\title{
DETERMINANTS OF ENTREPRENEURIAL INTENTIONS OF UNIVERSITY STUDENTS IN SELECTED POST-COMMUNIST COUNTRIES IN EUROPE: INVESTIGATING CROSS-CULTURAL DIFFERENCES
}

\author{
Mateusz TOMAL (D) ${ }^{*}$, Andrzej SZROMNIK (D)2, 3 \\ ${ }^{1}$ Department of Real Estate and Investment Economics, Cracow University of Economics, \\ Cracow, Poland \\ ${ }^{2}$ Department of Trade and Market Institutions, Cracow University of Economics, \\ Cracow, Poland \\ ${ }^{3}$ Department of Economics and Management, State Higher School of Technology \\ and Economics in Jarosław, Jarosław, Poland
}

Received 04 November 2020; accepted 21 June 2021; first published online 30 November 2021

\begin{abstract}
Main goal of this study is to explore the entrepreneurial intentions of students in selected European post-communist states. The second purpose of the research is to learn about those determinants which, according to the respondents themselves, are essential for the emergence of entrepreneurial intentions. In short, the results of hierarchical multiple OLS regression indicated that the most important factor influencing the entrepreneurial intentions of the surveyed students was entrepreneurial self-efficacy. Moreover, based on estimates of the final regression model, it was identified that dummy variables concerning the respondents' country significantly moderate the relationship between entrepreneurial self-efficacy and the dependent variable. It can be noted that the strength of the impact of the above-mentioned regressor is closely related to the values of Hofstede's dimensions of national culture. The obtained results were fully confirmed using an alternative research method, i.e. the ordered logit model. In the second stage of the study, it was revealed that the desire to be independent is the most frequently cited factor motivating the respondents to start their own business. Moreover, using the multiple marginal independence (MMI) testing method, it was found that student responses differ significantly among the examined countries, except for two cases, i.e. Russia and Latvia, and the Czech Republic and Slovakia.
\end{abstract}

Keywords: entrepreneurial intentions, self-efficacy, cross-cultural approach, hierarchical multiple OLS regression, multiple marginal independence testing, ordered logit model.

JEL Classification: M13, L26.

\footnotetext{
*Corresponding author. E-mail: tomalm@uek.krakow.pl
} 


\section{Introduction}

Entrepreneurship is one of the key factors determining economic development (Trung et al., 2020; Gubik, 2021; Boubker et al., 2021). Therefore, studies on entrepreneurship and, in particular, on entrepreneurial intentions have been the subject of many studies for over 30 years. Knowledge of the factors that drive individuals to take entrepreneurial action is extremely important for policy-makers, who can use it to formulate pro-entrepreneurial policies. It should be noted that the research conducted so far indicates the lack of one universal set of determinants shaping entrepreneurial intentions. On this basis, it can be concluded that there is need for further research in this area. This need is particularly evident in post-communist countries, where the free market has only recently been formed. Additionally, in the current scientific literature most of the research on entrepreneurial intentions concerns Western countries (Nowiński et al., 2019). Therefore, this article reduces the gap in the literature by examining the determinants of entrepreneurial intentions among Central and Eastern European (CEE) countries. The second goal of this study is to assess the cultural influence of the countries in question on the strength of the impact of the examined determinants on entrepreneurial intentions. It should be noted that according to Iakovleva and Solesvik (2014), research on the impact of cultural differences on the level of entrepreneurial intentions is still a black box. To the best of our knowledge, in the literature to date, only Moriano et al. (2012) have attempted to explain the above phenomenon, but they only addressed one dimension of culture, namely individualism. Therefore, this paper is a major contribution to the literature on the subject due to the fact that it is the first to examine the influence of four cultural dimensions (individualism, power distance, masculinity, uncertainty avoidance) on the strength of the impact of determinants of students' entrepreneurial intentions in Central and Eastern European countries.

In order to explain the entrepreneurial intentions of the surveyed students, the hierarchical multiple OLS regression method was used, which is common in this type of research (see, for example, Solesvik et al., 2013). In addition, an ordered logit model was used to model entrepreneurial intentions and check the reliability of the results obtained.

Moreover, it should be emphasised that, so far, research on the determinants of students' entrepreneurial intentions has not directly taken into account the opinions of the respondents. Therefore, the aim of this article is not only to identify objectively the factors influencing the propensity to set up a company, but also to learn about the determinants which, according to the interviewed persons themselves, are crucial in the context of entrepreneurial intentions. Furthermore, the significance of differences in the above-mentioned opinions in the countries in question was checked with the use of the multiple marginal independence (MMI) testing method, which to our knowledge is the first such analysis in the field of entrepreneurial intention research. An added value of this article is also the research sample considered. In particular, this study examines the entrepreneurial intentions of students from Poland, the Czech Republic, Slovakia, Latvia and Russia, which is pioneering.

The paper is organised as follows. Section 1 provides an overview of previous research on the determinants of entrepreneurial intentions of students in European post-communist countries. Section 2 describes the research sample and the methods used. In turn, Section 3 
presents the results of the empirical research conducted. This article ends with conclusions, the limitations of the research and directions for future study in the field of student entrepreneurial intentions.

\section{Main determinants of entrepreneurial intentions of students in European post-Communist countries}

\subsection{Entrepreneurial self-efficacy}

Self-efficacy concerns the individual perception of one's own abilities to perform a given activity. Therefore, in the context of this study, this factor will refer to one's own judgement of the capacity to be an entrepreneur. It should be noted that from a theoretical point of view, entrepreneurial self-efficacy is one of the main determinants explaining entrepreneurial intentions (Gill et al., 2021). In particular, this factor appears in two main theories used to identify entrepreneurial intentions, i.e. 1) the theory of planned behaviour, in which entrepreneurial self-efficacy is included in the perceived behavioural control constructs; and 2) the entrepreneurial event model, which refers directly to entrepreneurial self-efficacy (Nowiński \& Haddoud, 2019).

It should be noted that empirical studies to date also confirm the influence of entrepreneurial self-efficacy on entrepreneurial intentions. In particular, the research conducted by Pawlak (2016) and Wąsowska (2016) identified that entrepreneurial self-efficacy is the most important factor shaping entrepreneurial intentions among Polish students. The impact of this factor was also identified by Kurczewska and Białek (2014). The research carried out by these authors also concerned Polish students, but the results obtained indicated that selfefficacy is a significant, but weak determinant of entrepreneurial mindsets. In turn, Nowiński and Haddoud (2019) discovered that self-efficacy strengthens entrepreneurial intentions effectively only in combination with other factors.

A number of studies can also be cited, which analyse constructs of perceived behavioural control. Narrowing down the literature review to CEE countries, it should be stated that this variable also has positive impact on entrepreneurial intentions, as confirmed, among others, by Solesvik (2013).

\subsection{Entrepreneurial attitude}

According to the theory of planned behaviour, another extremely important factor shaping entrepreneurial intentions is the attitude towards entrepreneurship. Generally speaking, the attitude towards a given behaviour refers to an individual assessment (positive or negative) of the examined activity. Similarly, a more favourable perception of the outcomes of setting up a company implies a higher degree of entrepreneurial attitude, which positively influences entrepreneurial intentions (Ajzen, 1991). The latter relationship has been positively verified in a number of studies (see, for example, Solesvik, 2013; Wach \& Wojciechowski, 2016; Nowiński \& Haddoud, 2019). There are also studies, however, in which the analysed relation proved to be irrelevant (see, for example, Pawlak, 2016). 


\subsection{Entrepreneurial parental role model}

The literature increasingly recognises inspiring role models as important for the emergence of entrepreneurial intentions (Moussa \& Kerkeni, 2021; Abbasianchavari \& Moritz, 2021). Particular emphasis should be placed on entrepreneurial parental role models, i.e. it can be stated with a high probability that exposing a person to entrepreneurship in the context of one's closest family significantly increases his/her entrepreneurial intentions. The positive impact of family entrepreneurial background on the susceptibility to entrepreneurial mindsets has been confirmed, among others, in studies conducted by Ziemiański (2018), and Nowiński and Haddoud (2019) on a group of Polish students. Westhead and Solesvik (2016), who based their research on students from the Ukraine, also partially confirmed this dependence. In particular, the above authors estimated six regression models; however, only in one the studied relationship proved to be significant. The positive impact of the analysed phenomenon on entrepreneurial intentions was also identified in a study by Egerová et al. (2017), who analysed the intentions of Czech students.

It should be noted, however, that there are studies in which an insignificant relationship between the entrepreneurial parental role model and entrepreneurial intentions has been identified (see, for example, Solesvik, 2013; Solesvik et al., 2013, 2014; Wąsowska, 2016).

\subsection{Gender}

Analyses of the impact of gender on entrepreneurial intentions are also increasingly considered in existing research on entrepreneurship. The empirical results of these studies, however, are ambiguous. On the one hand, a number of studies has identified significant gender impact on entrepreneurial intentions (see Kurczewska \& Białek, 2014; Branchet \& Křížková, 2015; Westhead \& Solesvik, 2016; Çera et al., 2018; Ziemiański, 2018). On the other, there are several analyses stating the lack of gender impact on the willingness to undertake entrepreneurial activity (see, for example, Solesvik, 2013; Solesvik et al., 2013, 2014; Rantanen et al., 2015; Pawlak, 2016; Wąsowska, 2016).

In the case of CEE countries, the majority of studies which have identified significant gender impact on entrepreneurial intentions indicate that men are more likely to start a company (see, for example, Kurczewska \& Białek, 2014; Branchet \& Křrížková, 2015; Çera et al., 2018; Westhead \& Solesvik, 2016; Ziemiański, 2018).

\subsection{Cross-country differences: the cultural aspect}

It should be noted that the determinants of entrepreneurial intentions in the countries concerned might differ. In addition, differences may also be noted in the strength of influence of specific factors. These conclusions may be largely due to cultural heterogeneity between countries. One of the main dimensions of culture is individualism, juxtaposed by collectivism. With regard to the subject under consideration, the parental role model factor can be expected to have a stronger impact on entrepreneurial intentions in collectivist countries. This results from the fact that in such countries people are more inclined to succumb to their closest environment (Moriano et al., 2012). 
Another cultural dimension is uncertainty avoidance, which can be described as the degree of threat sensitivity by members of a given culture resulting from uncertain or unknown situations. It should be noted that the level of uncertainty avoidance in a particular country might significantly moderate the strength of influence of entrepreneurial attitude on entrepreneurial intentions. This is due to the fact that this cultural dimension is closely related to risk-taking (Anlesinya et al., 2019). In particular, members of cultures where there is a high level of uncertainty avoidance are more aware of the risks associated with setting up a business, which implies adopting a negative attitude towards entrepreneurship, perceived as something unattractive.

The last two dimensions of culture, i.e. power distance and masculinity, have a particular impact on the degree of entrepreneurial intentions among women. In particular, power distance concerns 'the extent to which less powerful members of institutions and organizations within a country expect and accept that power is distributed unequally' (Hofstede, 1991, p. 28). This dimension of culture emphasises the desire to maintain the status quo and a certain hierarchy in society. Therefore, in cultures where men are seen as the heads of the family, women very often cannot count on support to start their own businesses.

In terms of the masculinity dimension, different expectations between men and women are highlighted. In particular, women are focused on people and quality of life, while men are characterised by assertiveness, competitiveness and hardness, which can lead to a higher level of entrepreneurial intent among them. In contrast, in feminine cultures gender roles are similar.

Moreover, it can be assumed that all the above-mentioned dimensions of culture may be correlated with the level of entrepreneurial self-efficacy. In particular, it can be expected that in collectivist countries the strength of the impact of this variable on the formation of entrepreneurial intentions may be much higher. This is due to the fact that in this type of countries there is pressure for collective action. Overcoming this pressure may require a strong conviction of the individual's ability to be an entrepreneur. Entrepreneurial self-efficacy may also be crucial in determining entrepreneurial intentions in countries with high levels of power distance, whose societies are distinctly hierarchical. Consequently, "breaking out" of a certain established line requires that one also has a strong belief in one's intended actions. Entrepreneurial self-efficacy can also be crucial in breaking down barriers resulting from high levels of cultural masculinity and uncertainty avoidance. Such societies are characterised by the belief that only the best can succeed. As such, there is a sense of insecurity resulting from uncertain actions, including starting a business.

Cultural differences can also be seen in Central and Eastern European countries, which affects the determinants of entrepreneurial intentions. In particular, studies carried out by Çera et al. (2018) have shown that both in the Czech Republic and Slovakia men have a higher inclination to start a business. These results may be the effect of high levels of masculinity in these countries (see Table 1). In the discussed context, attention should also be paid to the impact of entrepreneurial self-efficacy on entrepreneurial intentions identified by Nowiński et al. (2019) in the Visegrad countries. The authors discovered significant differences between the examined countries in relation to the character of the relationship among the above variables. 
Conversely, one can point to the research conducted by Moriano et al. (2012), in which factors influencing the entrepreneurial intentions of students in India, Iran, Spain, Poland, Germany and the Netherlands were examined. The results obtained indicated that there are no differences in the strength of influence of entrepreneurial self-efficacy and entrepreneurial attitudes on entrepreneurial intentions in the studied countries.

Table 1. Values of Hofstede's dimensions of national culture for the selected post-communist countries in Europe (source: Hofstede Insights, 2020)

\begin{tabular}{|l|c|c|c|c|}
\hline \multicolumn{1}{|c|}{ Country } & Power Distance & Individualism & Masculinity & Uncertainty Avoidance \\
\hline Czech Republic & 57 & 58 & 57 & 74 \\
\hline Slovakia & 100 & 52 & 100 & 51 \\
\hline Poland & 68 & 60 & 64 & 93 \\
\hline Russia & 93 & 39 & 36 & 95 \\
\hline Latvia & 44 & 70 & 9 & 63 \\
\hline
\end{tabular}

\subsection{Research hypotheses}

On the basis of the literature review, it can be concluded that the only factor very likely to have a significant influence on entrepreneurial intentions is entrepreneurial self-efficacy, as the ambiguous results of other studies indicate that determinants such as gender, entrepreneurial attitude and the entrepreneurial parental role model may or may not have a significant impact on students' willingness to start a business. Therefore, on the basis of the above argumentation, we expect that

- Hypothesis 1 (H1): the main factor determining the entrepreneurial intentions of students in European post-communist countries is entrepreneurial self-efficacy.

Given hypothesis 1 and the international literature review suggesting that there may be significant differences in the level of influence of individual factors on entrepreneurial intentions, we postulate that

- Hypothesis 2 (H2): the strength of the impact of entrepreneurial self-efficacy on entrepreneurial intentions varies between the countries studied and depends on the cultural specificities of each country.

In particular, it can be predicted that in a society characterised by: (i) high level of hierarchisation (high level of power distance); (ii) increased feelings of insecurity as a result of uncertain actions (high level of uncertainty avoidance); (iii) pressure to act collectively (collectivism); (iv) the belief that only the best can succeed (masculinity), it is the individual's judgement of his or her ability to be an entrepreneur that may prove to be the key factor for overcoming these barriers to entrepreneurial action. Related to this, we presume that

- Hypothesis 3 (H3): the strength of the impact of entrepreneurial self-efficacy on entrepreneurial intentions is positively correlated with the following culture dimensions: power distance, uncertainty avoidance and masculinity. Conversely, a negative correlation can be expected with the culture dimension describing individualism.

Taking into account hypothesis 3 and the values of the culture dimensions presented in Table 1, we predict that 
- Hypothesis 4 (H4): entrepreneurial self-efficacy plays the least role in shaping students' entrepreneurial intentions in Latvia, whose society is characterised by significantly lower levels of power distance, collectivism and masculinity compared to the other countries in question.

\section{Methodology}

\subsection{Research sample}

The data for this analysis were obtained on the basis of a questionnaire survey, addressed to students of economics from the following academic institutions: (i) Poland - Cracow University of Economics, College of Economics, Finance and Law; University of Rzeszow, Institute of Economics and Finance; (ii) the Czech Republic - Technical University of Ostrava, Faculty of Economics; (iii) Slovakia - University of Economics in Bratislava, Faculty of Business Economy, Kosice branch; (iv) Russia - Plekhanov Russian University of Economics, Faculty of Economics and Law; (v) Latvia - Baltic International Academy, Faculty of Economics and Finance.

For the estimation of the hierarchical multiple OLS regression, 640 complete responses were obtained. Among them, the highest percentage included students from Poland $(\mathrm{N}=289)$ and Slovakia $(\mathrm{N}=119)$. The lowest included students from Latvia $(\mathrm{N}=73)$ and Russia $(\mathrm{N}=74)$. In turn, 85 students from the Czech Republic completed the questionnaire. Overall, 572 observations were used for econometric modelling of the determinants of students' entrepreneurial intentions, as 68 students did not express an opinion. In terms of surveys of students' own opinions on factors influencing the establishment of business activity, data from 638 persons were used.

\subsection{Hierarchical multiple OLS regression}

The hierarchical multiple OLS regression method will be used to identify the factors influencing students' entrepreneurial intentions. In particular, three regression models will be developed, the first of which will include only control variables:

$$
E I=\beta_{0}+\beta_{1} A g e+\beta_{2} P L+\varepsilon,
$$

where $E I$ denotes the entrepreneurial intention of a given respondent, Age is the age of a given respondent, $P L$ is the place of living of a given respondent, $\varepsilon$ is the error term, $\beta_{0}, \beta_{1}$, $\beta_{2}$ are the parameters of the model.

The second model will be extended with independent variables, i.e. ESE, EA, EPRM (see abbreviations list in Table 2) and Gender in order to capture their direct impact on the dependent variable, and will take the following form:

$$
E I=\beta_{0}+\beta_{1} A g e+\beta_{2} P L+\beta_{3} E S E+\beta_{4} E A+\beta_{5} E P R M+\beta_{6} \text { Gender }+\varepsilon,
$$

where ESE denotes the entrepreneurial self-efficacy of a given respondent, $E A$ is the entrepreneurial attitude of a given respondent, EPRM concerns the entrepreneurial parental role 
model of a given respondent, i.e. whether at least one of the respondent's parents is an active entrepreneur, while Gender is the gender of a given respondent.

The final regression model will include dummy variables concerning the analysed countries and interaction effects between them and the independent variables. This model will identify changes in the strength of influence of independent variables (ESE, EA, EPRM, Gender) on entrepreneurial intentions depending on a given country. This model will be expressed using the following formula:

$$
\begin{aligned}
& E I=\beta_{0}+\beta_{1} \text { Age }+\beta_{2} P L+\beta_{3} E S E+\beta_{4} E A+\beta_{5} E P R M+\beta_{6} \text { Gender }+\sum_{k=1}^{n-1} \alpha_{k} L_{k}+ \\
& \sum_{k=1}^{n-1} \gamma_{k} L_{k} E S E+\sum_{k=1}^{n-1} \delta_{k} L_{k} E A+\sum_{k=1}^{n-1} \theta_{k} L_{k} E P R M+\sum_{k=1}^{n-1} \varphi_{k} L_{k} \text { Gender }+\varepsilon,
\end{aligned}
$$

where $L_{1}, \ldots, L_{k}$ is a set of dummy variables considering the localisation of a given respondent (Poland, the Czech Republic, Slovakia, Latvia, Russia), $n$ denotes the number of studied countries, $\alpha_{k}, \gamma_{k}, \varphi_{k}, \theta_{k}, \delta_{k}$ are the parameters of the model.

\begin{tabular}{|c|c|c|c|}
\hline Variables & Description & Min & Max \\
\hline \multicolumn{4}{|c|}{ Dependent variable } \\
\hline $\begin{array}{l}\text { Entrepreneurial } \\
\text { Intention }(E I)\end{array}$ & $\begin{array}{l}\text { Answer of a given respondent to the question: Are you } \\
\text { considering starting your own business? } \\
\text { Possible answers: } 1 \text { - definitely not, } 2 \text { - no, } 3 \text { - rather } \\
\text { not, } 4 \text { - rather yes, } 5 \text { - yes, } 6 \text { - definitely yes. }\end{array}$ & 1 & 7 \\
\hline \multicolumn{4}{|c|}{ Control variables } \\
\hline Age & Age of a given respondent & 16 & 29 \\
\hline $\begin{array}{l}\text { Place of living } \\
(P L)\end{array}$ & $\begin{array}{l}\text { Place of living of a given respondent: } 0 \text { - rural areas, } \\
1 \text { - urban areas. }\end{array}$ & 0 & 1 \\
\hline \multicolumn{4}{|c|}{ Independent variables } \\
\hline $\begin{array}{l}\text { Entrepreneurial } \\
\text { self-efficacy (ESE) }\end{array}$ & $\begin{array}{l}\text { Answer of a given respondent to the question: Do you } \\
\text { think that you could be an entrepreneur? } \\
\text { Possible answers: } 1 \text { - definitely not, } 2 \text { - no, } 3 \text { - rather } \\
\text { not, } 4 \text { - rather yes, } 5 \text { - definitely yes. }\end{array}$ & 1 & 5 \\
\hline $\begin{array}{l}\text { Entrepreneurial } \\
\text { attitude }(E A)\end{array}$ & $\begin{array}{l}\text { Answer of a given respondent to the question: How do } \\
\text { you assess the chances of new companies on the market? } \\
\text { Possible answers: } 1 \text { - unfavourable, } 2 \text { - hard to say, } 3 \text { - } \\
\text { favourable. }\end{array}$ & 1 & 3 \\
\hline $\begin{array}{l}\text { Entrepreneurial } \\
\text { parental role } \\
\text { model }(E P R M)\end{array}$ & $\begin{array}{l}\text { The variable takes the value } 1 \text { if at least one of the } \\
\text { parents of the respondent is an entrepreneur, } 0 \\
\text { otherwise. }\end{array}$ & 0 & 1 \\
\hline Gender & Gender of a given respondent: 0 - male, 1 - female. & 0 & 1 \\
\hline \multicolumn{4}{|c|}{ Moderators } \\
\hline$L_{1}$ & $\begin{array}{l}\text { Country a given respondent: } \\
0 \text { - otherwise, } 1 \text { - Poland. }\end{array}$ & 0 & 1 \\
\hline
\end{tabular}

Table 2. Description of variables used in the hierarchical multiple OLS regression 
End of Table 2

\begin{tabular}{|l|l|c|c|}
\hline \multicolumn{1}{|c|}{ Variables } & \multicolumn{1}{|c|}{ Description } & Min & Max \\
\hline$L_{2}$ & $\begin{array}{l}\text { Country a given respondent: } \\
0-\text { otherwise, } 1-\text { the Czech Republic. }\end{array}$ & 0 & 1 \\
\hline$L_{3}$ & $\begin{array}{l}\text { Country a given respondent: } \\
0-\text { otherwise, } 1-\text { Slovakia. }\end{array}$ & 0 & 1 \\
\hline$L_{4}$ & $\begin{array}{l}\text { Country a given respondent: } \\
0-\text { otherwise, } 1-\text { Russia. }\end{array}$ & 0 & 1 \\
\hline $\begin{array}{l}L_{5} \text { (baseline } \\
\text { category) }\end{array}$ & $\begin{array}{l}\text { Country a given respondent: } \\
0-\text { otherwise, } 1-\text { Latvia. }\end{array}$ & 0 & 1 \\
\hline
\end{tabular}

\subsection{Multiple marginal independence testing}

The second aim of this study is to learn about the factors which, in the opinion of students themselves, encourage them to start a business. In this respect, an appropriate multiplechoice question was included in the questionnaire. Students were asked to mark three sources of motivation out of 11 which, in their opinion, affected the establishment of one's own business (see Table 3).

Table 3. Description of the question concerning the factors encouraging students to start a company

\begin{tabular}{|c|c|}
\hline The question & Possible answers (Required number of answers: 3 ) \\
\hline $\begin{array}{l}\text { What do you think } \\
\text { encourages you to start } \\
\text { your own business? }\end{array}$ & $\begin{array}{l}\text { A. Independence - "I want to be independent" } \\
\text { B. Flexible working hours - "I can work the hours I want" } \\
\text { C. Higher earnings - "I'll earn more than in a regular job" } \\
\text { D. Realising my own interests - "I can combine work with passion" } \\
\text { E. Family business - "I will take over the family business" } \\
\text { F. Type of entrepreneurial personality - "I think I'm fit for it" } \\
\text { G. Unique business idea - "I have a great idea" } \\
\text { H. Wanting to work on my own - "I don't want to work with someone" } \\
\text { I. Willingness to take risks - "I like the risks involved in making } \\
\text { important decisions" } \\
\text { J. Lack of job offers - "There are no jobs, there is high unemployment" } \\
\text { K. Capital held - "I have money I want to invest" }\end{array}$ \\
\hline
\end{tabular}

In the context of this article, it is interesting to know whether the answers of the respondents from various locations differ significantly. The traditional Pearson chi-square test for independence cannot be used in this study because the subject involves multiple-response categorical variables, which cause within-subject dependence among responses (Bilder et al., 2000; Bilder \& Loughin, 2004). Therefore, one of the so-called multiple marginal independence testing methods, in particular the non-parametric bootstrap procedure, which is based on a modified version of the Pearson chi-square test statistic, will be used to identify the significance of differences in student responses in the countries in question. The above methods are used to test the independence of two categorical variables in which only one can be a multiple-response variable. MMI testing methods adopt a null hypothesis, which states that the tested variables are marginally independent. In the case of this study, the research 
problem is to determine whether the responses to the question in Table 3 are marginally independent of localisation.

\section{Research results}

\subsection{Exploring determinants of entrepreneurial intentions: hierarchical multiple OLS regression results}

In the first stage of the empirical study, hierarchical multiple OLS regression analysis was used to explain the dependent variable that describes the students' entrepreneurial intentions. The results of the estimation of all regression models are presented in Table 4 . It should be noted that all models turned out to be significant at a level of 0.01 .

In model 1 , only control variables were included. The estimation results showed that both variables, i.e. Age and $P L$ are statically significant. In particular, with age, the propensity of students to start a company decreases, which is consistent with studies conducted by Bell (2019). The identified relationship between age and entrepreneurial intentions may be due to the fact that older people are more aware of potential risks, including the risk of failure of a newly established business, and therefore prefer to avoid this type of uncertain activity (Schwarz et al., 2009). Starting a business also requires investing a lot of time, and older people, as Lévesque and Minniti (2006) note, are less likely to devote time to activities with a long payback period, which further explains the negative relationship between age and entrepreneurial intentions. With regard to the second control variable, living in urban areas significantly increases the entrepreneurial intentions of students. This result is not surprising, as there are much better opportunities to set up and run a business in urban areas. In addition, rural areas have significantly higher barriers to starting a business, which include lack of access to financial resources and knowledge in establishing a new company (Capelleras et al., 2013).

Model 2 includes, in addition to control variables, predefined independent variables. The obtained results indicate that all variables in this model, both control and independent, turned out to be statically significant. In particular, by analysing the standardised coefficients, it can be concluded that the variable concerning entrepreneurial self-efficacy has the strongest positive influence on students' entrepreneurial intentions. It should also be noted that this result is consistent with other studies covering post-communist countries in Europe (described in section 1.1), as well as analyses carried out among students elsewhere (see, for example, Pfeifer et al., 2016). The above result also has very important implications for university educators. In particular, by increasing students' self-confidence, their entrepreneurial intentions can be substantially enhanced, which can bring tangible benefits to the economy in the future. To this end, it is necessary not only to focus on learning theoretical issues, but also to introduce innovative teaching methods, such as educational games for running one's own business.

It should be stressed that the estimated parameters of model 2 for the remaining independent variables are also consistent with other studies conducted thus far (see, for example, Moreno-Gómez et al., 2019). In particular, a positive relationship between entrepreneurial 
attitude/family entrepreneurial background and entrepreneurial intentions can be observed. The strength of the impact of the latter two factors, however, is much smaller than the variable describing entrepreneurial self-efficacy. In this regard, special attention should be paid to entrepreneurial attitude, which, according to the theory of planned behaviour, is the most important factor of any behaviour (Ajzen, 1991). Based on model 2, however, it can be concluded that this variable has the least influence on the formation of students' entrepreneurial intentions. Following Zhang et al. (2015), this can be explained by the fact that students do not have entrepreneurial experience and, therefore, are not able to identify the opportunities and risks of establishing a business, which makes the strength of the correlation between attitude and intentions low.

In turn, when analysing the strength of the entrepreneurial parental role model variable on the dependent variable, it should be concluded that although being brought up in an entrepreneurial family increases the likelihood of a student starting their own business, this factor is much weaker in shaping entrepreneurial intentions than one's own judgement to be an entrepreneur, which supports the conclusions drawn by Zhang et al. (2015) that nature is more important than upbringing in shaping students' entrepreneurial intentions.

In the case of the gender variable, the results show that women are less willing to start a business than men. These estimates are not surprising given the high levels of the power distance and masculinity dimensions in the countries surveyed (see Table 1). It should also be noted that the results obtained regarding the influence of gender on entrepreneurial intentions are also in line with those obtained in countries outside the CEE. As an example, a study conducted among students in the USA by Shinnar et al. (2014) can be mentioned here.

Table 4. Parameter estimates of hierarchical multiple OLS regression

\begin{tabular}{|c|c|c|c|}
\hline Variables & Model 1 & Model 2 & Model 3 \\
\hline Constant & $5.71^{\star * \star}$ & $3.63^{* * *}$ & $4.21^{\star * *}$ \\
\hline \multicolumn{4}{|c|}{ Controls } \\
\hline Age & $-0.09^{\star \star \star}(-0.18)$ & $-0.09^{\star \star \star}(-0.17)$ & $-0.06^{*}(-0.11)$ \\
\hline Place of living (PL) & $0.34^{\star * *}(0.16)$ & $0.12^{*}(0.06)$ & $0.08(0.04)$ \\
\hline \multicolumn{4}{|c|}{ Independent variables } \\
\hline $\begin{array}{l}\text { Entrepreneurial self-efficacy } \\
(E S E)\end{array}$ & & $0.56^{\star * *}(0.52)$ & $0.22(0.20)$ \\
\hline Entrepreneurial attitude $(E A)$ & & $0.11^{\star \star}(0.08)$ & $0.23(0.18)$ \\
\hline $\begin{array}{l}\text { Entrepreneurial parental role } \\
\text { model }(E P R M)\end{array}$ & & $0.23^{\star \star \star}(0.10)$ & $0.06(0.03)$ \\
\hline Gender & & $-0.25^{\star * \star}(-0.11)$ & $-0.13(-0.06)$ \\
\hline \multicolumn{4}{|c|}{ Moderators } \\
\hline$L_{1}($ Poland $)$ & & & $-1.19^{*}(-0.57)$ \\
\hline$L_{2}$ (Czech Republic) & & & $-1.75^{\star \star}(-0.67)$ \\
\hline$L_{3}($ Slovakia $)$ & & & $-1.40^{*}(-0.54)$ \\
\hline$L_{4}$ (Russia) & & & $-2.19^{\star \star \star}(-0.68)$ \\
\hline
\end{tabular}


End of Table 4

\begin{tabular}{|c|c|c|c|}
\hline Variables & Model 1 & Model 2 & Model 3 \\
\hline$L_{5}$ (Latvia) - baseline category & & & - \\
\hline
\end{tabular}

\begin{tabular}{|l|l|l|c|}
\hline \multicolumn{3}{|c|}{ Interaction effects } \\
\hline$L_{1} \times E S E$ & & & $0.31^{\star}(0.56)$ \\
\hline$L_{2} \times E S E$ & & & $0.41^{\star *}(0.50)$ \\
\hline$L_{3} \times E S E$ & & & $0.35^{\star *}(0.52)$ \\
\hline$L_{4} \times E S E$ & & & $0.69^{* * *}(0.88)$ \\
\hline$L_{1} \times E A$ & & & $-0.17(-0.19)$ \\
\hline$L_{2} \times E A$ & & & $-0.01(-0.01)$ \\
\hline$L_{3} \times E A$ & & & $-0.10(-0.07)$ \\
\hline$L_{4} \times E A$ & & & $-0.42^{\star *}(-0.28)$ \\
\hline$L_{1} \times E P R M$ & & & $0.19(0.06)$ \\
\hline$L_{2} \times E P R M$ & & & $0.33(0.06)$ \\
\hline$L_{3} \times E P R M$ & & & $0.26(0.06)$ \\
\hline$L_{4} \times E P R M$ & & & $0.29(0.06)$ \\
\hline$L_{1} \times$ Gender & & & $0.07(0.03)$ \\
\hline$L_{2} \times$ Gender & & & $-0.16(-0.04)$ \\
\hline$L_{3} \times$ Gender & & & $-0.20(-0.07)$ \\
\hline$L_{4} \times$ Gender & & & $0.21(0.06)$ \\
\hline Adjusted R2 & & & 0.43 \\
\hline$F$-test $p$-value & & & 0.00 \\
\hline $\mathrm{N}$ & & & 572 \\
\hline
\end{tabular}

Notes: Regressions with robust standard errors. In parentheses, standardised regression coefficients. ${ }^{* *}$ $\mathrm{p}<0.01 ;{ }^{* *} \mathrm{p}<0.05$; $^{\star} \mathrm{p}<0.10$.

In the last regression model, moderating variables and interaction effects were taken into account in order to examine whether the strength of the influence of independent variables on entrepreneurial intentions differs significantly in the studied countries. The results of the estimation indicate that all moderating variables turned out to be significant. In particular, the estimated parameters demonstrate that students from Latvia (baseline category) are on average the most likely to set up a business. In turn, students from Russia are least interested in the possibility of setting up a new company, as evidenced by the highest value of the estimated parameter among moderating variables $\left(\alpha_{4}=-2.19\right)$. The very low level of entrepreneurial intentions among Russian students may be due to several reasons. First of all, as Iakovleva and Solesvik (2014) note, the Russian government is not oriented towards entrepreneurship, which manifests itself through unfavourable legal regulations for entrepreneurs, such as high taxes, inflation, unstable legal system and lack of access to capital for start-ups. Furthermore, according to a study conducted by Kofanova (1997), in Russia a very large proportion of entrepreneurs felt pressure from criminals, which may further weaken the desire of young people to start a business. 
The very low entrepreneurial intentions among Czech students, compared to neighbouring countries (Poland and Slovakia), should also be noted. The latter findings are confirmed by other scientific studies carried out, among others, by Çera et al. (2018) and Okręglicka et al. (2017). This may be a result of the complete suspension of entrepreneurship in the Czech Republic during the communist period, which has not been experienced in other Central and Eastern European countries (Branchet \& Křížková, 2015).

Returning to the estimates of model 3, it can be observed that significant interaction effects occur mainly for the independent variable describing entrepreneurial self-efficacy. In particular, it can be noted that students' entrepreneurial intentions are most strongly influenced by this variable in Russia $\left(\gamma_{4} E S E=0.69 E S E\right)$, and least so in Latvia $\left(\beta_{3} E S E=0.22 E S E\right)$. To further analyse the above results, Figure 1 shows the two-way interaction relationship between ESE and student's country of residence on entrepreneurial intention. Based on the simple slope analysis estimates, it can be concluded that for students from all countries, there is a positive relationship between entrepreneurial self-efficacy and propensity to start a business. However, only for Latvian students the above-mentioned relationship turned out to be non-significant $\left(t_{\text {Latvia }}=1.35, p>0.10\right)$ and therefore it can be concluded that the level of entrepreneurial intention for these students remains the same regardless of whether they declare low or high entrepreneurial self-efficacy. On the other hand, students from Poland, Czech Republic, Slovakia and Russia reporting high entrepreneurial self-efficacy declared statistically higher level of entrepreneurial intention $\left(t_{\text {Poland }}=9.52, p<0.05 ; t_{\text {Czech Republic }}=\right.$ $\left.7.56, p<0.05 ; t_{\text {Slovakia }}=8.03, p<0.05 ; t_{\text {Russia }}=9.82, p<0.05\right)$. This fact is especially true for students from Russia as can be observed in Figure 1.

The question, however, arises as on what these differences depend. To this end, Figure 2 shows the relationship between the strength of the impact of the entrepreneurial self-efficacy variable and the values characterising the countries in question in terms of the cultural dimensions presented in Table 1. On the basis of Figure 2, it can be seen that the higher the values of power distance, uncertainty avoidance and masculinity, the greater the importance of entrepreneurial self-efficacy. In turn, an inverse relationship can be observed in reference to the cultural dimension describing individualism. In particular, countries with a high level of individualism are characterised by the low impact of entrepreneurial self-efficacy on

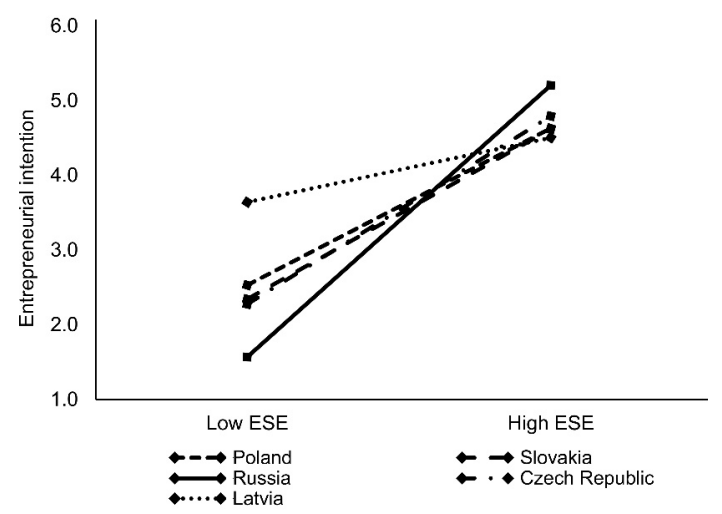

Figure 1. Two-way interaction relationship between ESE and student's country of residence on entrepreneurial intention 

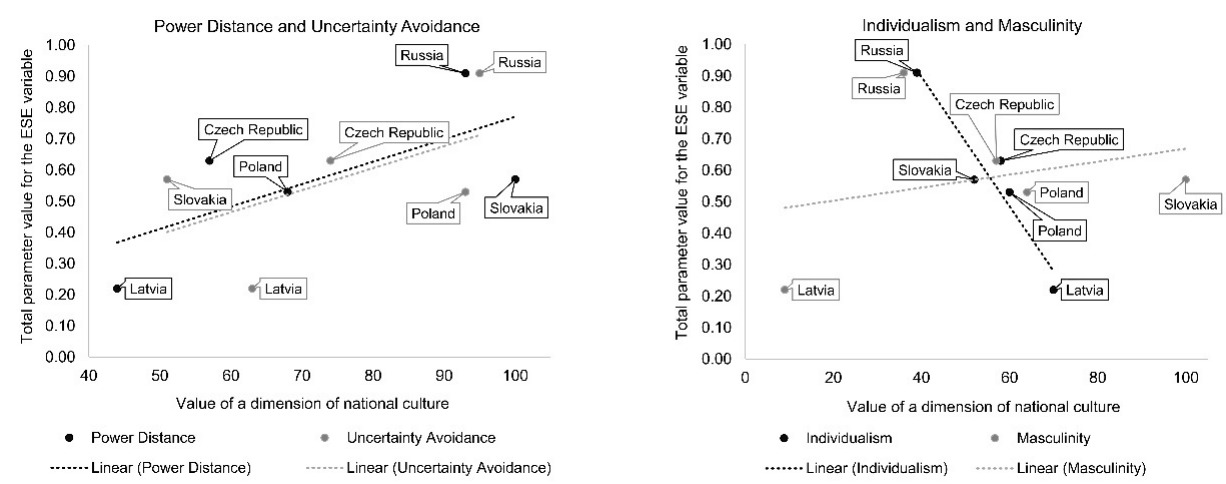

Figure 2. The relationship between the entrepreneurial self-efficacy variable and the values characterising the countries in question in terms of the cultural dimensions

entrepreneurial intentions. All the above relations are expected, because in societies where there are significant cultural barriers to individual entrepreneurial intentions (e.g. high level of society hierarchisation, feeling of threat as a result of uncertain actions, pressure for collective action etc.), high self-confidence of a given person may be crucial in overcoming them.

\subsection{Exploring determinants of entrepreneurial intentions: robustness checks}

It should be noted that the dependent variable used in this study takes an ordering of values from 1 to 6 . Therefore, modelling it with a simple multiple linear regression may lead to biased estimates due to the violation of the assumptions of the OLS method. As such, in this study, in order to test the results estimated in subsection 3.1, an alternative approach, i.e. the ordered logit model (OLOGIT), will be used to explore the determinants of students' entrepreneurial intentions. The OLOGIT model can be presented in general form as follows (Fullerton, 2009):

$$
\log \left(\frac{\operatorname{Pr}(y \leq m \mid \mathbf{x})}{\operatorname{Pr}(y>m \mid \mathbf{x})}\right)=\tau_{m}-\mathbf{x} \boldsymbol{\beta} \quad(1 \leq m<M)
$$

where $y$ is a dependent variable with $M$ categories (in this survey, the category means the student's response to the question about wanting to set up a business), $\mathbf{x}$ is a vector of independent variables, $\boldsymbol{\beta}$ is a vector of model parameters, $\tau$ is a cut point.

The results of the estimation of ordered logit models are presented in Table 5. When analysing the models without interactive effects, it should be emphasised that the results are very compatible with those obtained on the basis of OLS regression (see Table 4). In particular, people with higher self-efficacy and entrepreneurial attitude, as well as those whose parents are entrepreneurs, show higher entrepreneurial intentions. Also, the findings regarding the effect of gender on the explanatory variable were confirmed by the logit models, i.e. with other variables unchanged (being female causes a decrease of 0.57 in the log odds of being in a higher level of dependent variable). By examining the strength of the influence of individual independent variables on students' entrepreneurial intentions using OLOGIT models, 
the conclusions drawn from the OLS regressions estimates can also be fully confirmed. In particular, entrepreneurial self-efficacy is the main driver of the dependent variable, which ultimately positively verifies $\mathrm{H} 1$.

Table 5. Parameter estimates of hierarchical ordered logit model

\begin{tabular}{|c|c|c|c|}
\hline Variables & Model 1 & Model 2 & Model 3 \\
\hline \multicolumn{4}{|c|}{ Controls } \\
\hline Age & $-0.19^{\star * \star}(-0.36)$ & $-0.21^{\star \star \star}(-0.39)$ & $-0.13(-0.11)$ \\
\hline Place of living $(P L)$ & $0.58^{\star * \star}(0.28)$ & $0.28(0.13)$ & $0.15(0.04)$ \\
\hline \multicolumn{4}{|c|}{ Independent variables } \\
\hline Entrepreneurial self-efficacy (ESE) & & $1.40^{\star * *}(1.30)$ & $0.56(0.20)$ \\
\hline Entrepreneurial attitude $(E A)$ & & $0.27^{\star \star}(0.20)$ & $0.59(0.18)$ \\
\hline Entrepreneurial parental role model (EPRM) & & $0.50^{\star * \star}(0.22)$ & $-0.05(0.03)$ \\
\hline Gender & & $-0.57^{\star \star \star}(-0.25)$ & $-0.39(-0.06)$ \\
\hline \multicolumn{4}{|c|}{ Moderators } \\
\hline$L_{1}$ (Poland) & & & $-3.41^{\star}(-0.57)$ \\
\hline$L_{2}$ (Czech Republic) & & & $-5.12^{\star \star}(-0.67)$ \\
\hline$L_{3}$ (Slovakia) & & & $-3.59 *(-0.54)$ \\
\hline$L_{4}$ (Russia) & & & $-6.27^{* * *}(-0.68)$ \\
\hline$L_{5}$ (Latvia) - baseline category & & & - \\
\hline \multicolumn{4}{|c|}{ Interaction effects } \\
\hline$L_{1} \times E S E$ & & & $0.85^{\star}(0.56)$ \\
\hline$L_{2} \times E S E$ & & & $1.10^{\star *}(0.50)$ \\
\hline$L_{3} \times E S E$ & & & $0.89^{\star \star}(0.52)$ \\
\hline$L_{4} \times E S E$ & & & $1.83^{\star * \star}(0.88)$ \\
\hline$L_{1} \times E A$ & & & $-0.44(-0.19)$ \\
\hline$L_{2} \times E A$ & & & $0.05(-0.01)$ \\
\hline$L_{3} \times E A$ & & & $-0.31(-0.07)$ \\
\hline$L_{4} \times E A$ & & & $-0.97^{\star \star}(-0.28)$ \\
\hline$L_{1} \times E P R M$ & & & $0.60(0.06)$ \\
\hline$L_{2} \times E P R M$ & & & $1.11(0.06)$ \\
\hline$L_{3} \times E P R M$ & & & $0.83(0.06)$ \\
\hline$L_{4} \times E P R M$ & & & $1.08(0.06)$ \\
\hline$L_{1} \times$ Gender & & & $0.23(0.03)$ \\
\hline$L_{2} \times$ Gender & & & $-0.10(-0.04)$ \\
\hline$L_{3} \times$ Gender & & & $-0.49(-0.07)$ \\
\hline$L_{4} \times$ Gender & & & $0.63(0.06)$ \\
\hline Number of cases of correct prediction & $42.0 \%$ & $48.1 \%$ & $49.7 \%$ \\
\hline $\mathrm{N}$ & 572 & 572 & 572 \\
\hline
\end{tabular}

Notes: Regressions with robust standard errors. In parentheses, standardised regression coefficients. ${ }^{* *}$ $\mathrm{p}<0.01 ;{ }^{* *} \mathrm{p}<0.05 ;{ }^{*} \mathrm{p}<0.10$. 
In the third logit model, the set of explanatory variables was supplemented by moderating and interacting variables. In terms of the latter, mainly those related to entrepreneurial self-efficacy were found to be significant, indicating a variation in the strength of the impact of this independent variable on entrepreneurial intentions between the countries studied. At the same time, this result is in full agreement with the estimates obtained with the original methodology, and allows for a positive verification of $\mathrm{H} 2$.

In the next stage of the study, the relationship between the strength of the impact of entrepreneurial self-efficacy on the dependent variable and the characteristics of the societies of the studied countries in terms of the culture dimensions defined in Table 1 was checked using the Pearson correlation coefficient. The results obtained from the logit model are almost identical to those from the ordinary multiple linear regression, as shown in Figure 3. It should also be emphasised, however, that only for the cultural dimension describing individualism the estimated correlation coefficients are significant at the $10 \%$ level. Therefore, $\mathrm{H} 3$ can be confirmed only partially. Conversely, H4, which states that the entrepreneurial self-efficacy variable plays the smallest role in shaping students' entrepreneurial intentions in Latvia, can be fully positively verified. In particular, both estimated models 3 (see Tables 4 and 5) support these conclusions.

\subsection{Exploring motivating factors of entrepreneurial intentions: multiple marginal independence testing results}

The next stage of the study examined the factors which, in the opinion of students, encourage them to start a business. The overall results of this analysis are presented in Table 6. In particular, it can be noted that among the entire surveyed group of students, the most frequently indicated motivating factor to set up a business was the desire to be independent $(53.92 \%$ responses). This may have been influenced by the fact that this answer appeared first in the multiple-choice list. Therefore, there is a high probability that some students might not have read all the answers, choosing the first available option. Conversely, factor J ("There are no jobs, there is high unemployment") was rarely indicated as a source of motivation (5.96\% responses).

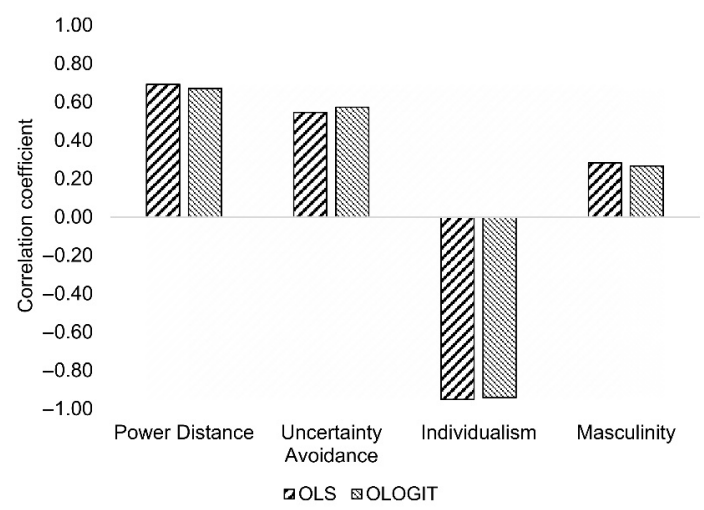

Figure 3. Correlation between the level of culture dimensions of the studied countries and the strength of the impact of entrepreneurial self-efficacy on students' entrepreneurial intentions 
M. Tomal, A. Szromnik. Determinants of entrepreneurial intentions of university students in selected...

\begin{tabular}{|c|c|c|c|c|c|c|c|}
\hline$\stackrel{\infty}{\tilde{\sigma}}$ & $\stackrel{\text { }}{\curvearrowright}$ & $\underset{ }{\stackrel{\circ}{O}}$ & $\Re$ & $\infty$ & $\curvearrowright$ & 氶蒡 & \\
\hline 늠 & 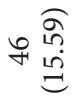 & 을 & $a \stackrel{\overparen{m}}{\stackrel{\Xi}{\Xi}}$ & 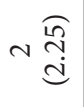 & 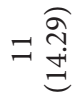 & 芌 & $\mathscr{Z}$ \\
\hline 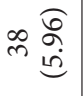 & 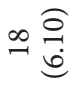 & 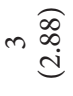 & 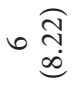 & 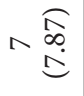 & $+\frac{\widehat{\partial}}{\sqrt{n}}$ & 苛 & - \\
\hline 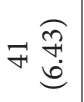 & $=\frac{\widehat{n}}{\stackrel{c}{c}}$ & 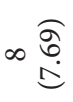 & 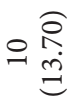 & $\sim \stackrel{\overparen{\mathscr{S}}}{\stackrel{d}{d}}$ & $\circ \stackrel{\widehat{\sigma}}{\stackrel{\Xi}{\Xi}}$ & $\vec{\Xi} \precsim$ & $\curvearrowleft$ \\
\hline 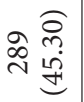 & 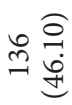 & 䏠 & 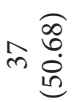 & 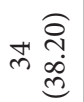 & 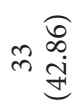 & 苛 & I \\
\hline 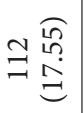 & 今 & $=\stackrel{\substack{\stackrel{\infty}{n} \\
\varrho}}{\varrho}$ & 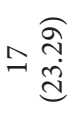 & 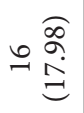 & 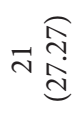 & $\widehat{\Xi})$ & $\circlearrowleft$ \\
\hline 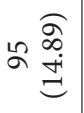 & 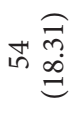 & $\wedge \stackrel{\widehat{n}}{\hat{\theta}}$ & 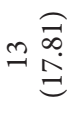 & 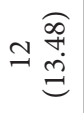 & $a \stackrel{\widehat{\hat{\sigma}}}{\Xi}$ & 苛 & I \\
\hline ↔ & $\approx \stackrel{6}{\stackrel{+}{+}}$ & 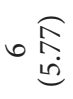 & 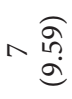 & 的 $\begin{array}{l}\widehat{\sigma} \\
\text { ind }\end{array}$ & m $\underset{\hat{a}}{\stackrel{\varrho}{్}}$ & 苛 & 디 \\
\hline 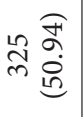 & 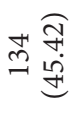 & 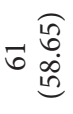 & 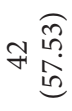 & 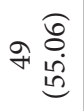 & m & 苛 & D \\
\hline $\begin{array}{l}\infty \underset{\hat{n}}{\widehat{N}} \\
\stackrel{\leftrightarrow}{\mathrm{g}}\end{array}$ & ᄋ & 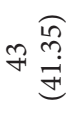 & 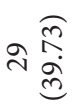 & 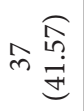 & ले & 苛 & 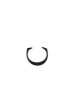 \\
\hline 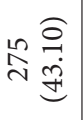 & 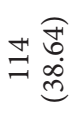 & 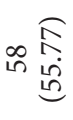 & 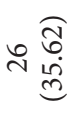 & 남 & m & 苛 & 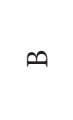 \\
\hline 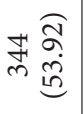 & 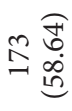 & ه & $\approx \frac{\widehat{\vec{n}}}{\frac{\vec{n}}{\sqrt{n}}}$ & in $\begin{array}{c}\text { f } \\
\text { fi }\end{array}$ & m & 苛 & $\varangle$ \\
\hline 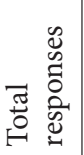 & $\begin{array}{l}\overrightarrow{0} \\
\frac{\overrightarrow{0}}{0} \\
\text { م }\end{array}$ & $\begin{array}{l}\frac{\pi}{3} \\
\frac{\pi}{\sigma} \\
\frac{0}{\infty}\end{array}$ & 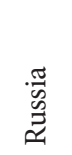 & 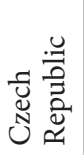 & 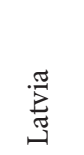 & : & 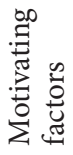 \\
\hline
\end{tabular}


It should be noted that there is a high probability that the structure of the responses in Table 6 differs significantly depending on the country. Therefore, using the non-parametric bootstrap procedure described in section 2.3, the obtained answers were checked for being marginally independent of localisation (country). All examined countries were taken into account in this. The p-value of the MMI testing method was 0.001 , which indicates that the responses differ significantly across countries.

It is also extremely interesting to discover from where the above result stems. To this end, all answers obtained for each country were analysed separately. The results of this examination are presented in Table 7 , on the basis of which it can be concluded that there are only two cases of insignificant differences among the studied countries, namely the cases of Slovakia and the Czech Republic, and Russia and Latvia. It should be noted that this type of outcome is not surprising. In the first case, i.e. the Czech Republic and Slovakia, it may be due to the common history of these countries, which until 1992 constituted one state. In the case of Russia and Latvia, it should be noted that there are also very strong ties between these countries, which may prescribe the similarities in student opinions. In support of this fact, one should point out the demographic data for Latvia, according to which as much as $24.9 \%$ of the population are Russians (Central Statistical Bureau of Latvia, 2019).

Table 7. Non-parametric bootstrap method p-values

\begin{tabular}{|l|c|c|c|c|}
\hline \multicolumn{1}{|c|}{ Country } & Poland & Slovakia & Russia & Czech Republic \\
\hline Slovakia & $0.001^{* * *}$ & & & \\
\hline Russia & $0.001^{* * *}$ & $0.001^{* * *}$ & & \\
\hline Czech Republic & $0.017^{* *}$ & 0.228 & $0.001^{* * *}$ & \\
\hline Latvia & $0.007^{* * *}$ & $0.010^{* *}$ & 0.600 & $0.001^{* * *}$ \\
\hline
\end{tabular}

Notes: ${ }^{* *} \mathrm{p}<0.01 ;{ }^{* *} \mathrm{p}<0.05 ;^{*} \mathrm{p}<0.10$.

\section{Conclusions}

This study attempts to identify factors that significantly influence the entrepreneurial intentions of students in Poland, the Czech Republic, Slovakia, Russia and Latvia. An empirical study conducted using the hierarchical multiple OLS regression method indicated that the willingness to start a business is mainly determined by entrepreneurial self-efficacy. Moreover, the results of the estimation of the regression model, which took into account moderating variables and interaction effects, show that the strength of the influence of entrepreneurial self-efficacy on students' entrepreneurial intentions varies among the countries studied and depends on cultural specificities. The above results were fully confirmed using an alternative research method, i.e. the ordered logit model. In the second stage of the study, the opinions of students identifying the three main motivating factors for starting a company were analysed. Based on the marginal table created for this multiple-choice question, it was revealed that the desire to be independent was the most popular choice. 
An MMI testing method was used to check whether the obtained responses differed significantly among the countries studied. The results of the above analysis showed that only Slovakia and the Czech Republic, and Russia and Latvia did not have significantly different student opinions.

It is important to note that this study has important implications for academic pedagogy. In particular, educators should shape students' entrepreneurial self-efficacy, which was found to be the most important determinant of their entrepreneurial intentions. However, this type of activity should take place especially in Russia, and to a much lesser extent in Latvia due to significant disparities between the strength of the impact of this factor on students' intention to start a business. In addition, due to the fact that as students grow older they are less inclined to start a business, the university authorities should adapt the curriculum in such a way that there is no lack of subjects supporting the interest in entrepreneurship throughout the education. Support aimed at sustaining entrepreneurial interest among students should also be provided after graduation. There are also implications for local and central government. In particular, they should help students from rural areas through various programs facilitating the establishment and later running of their own businesses.

It should be noted that this study has certain limitations. First of all, the test sample has not been selected at random. Such a situation, however, is common in research on students' entrepreneurial intentions and does not discredit the results obtained. Further, students from other post-communist countries in Europe were not included in this study. Therefore, future studies may extend the geographical coverage of the countries surveyed. In addition, analyses taking into account students from different fields would also be desirable, because, as indicated by other studies, the average level of entrepreneurial intention differs significantly between students of various faculties. Moreover, future research to confirm the results obtained may adopt a different specification of the models, the estimates of which are presented in Tables 4 and 5. In particular, it is likely that controls, as well as independent variables, may interact with students' entrepreneurial intentions in a non-linear way. Finally, as some of the correlation coefficients depicted in Figure 3 did not prove to be significant, future research should focus on further examining the relationship between the strength of the impact of entrepreneurial self-efficacy on entrepreneurial intentions and the cultural dimensions of power distance, masculinity and uncertainty avoidance.

\section{Acknowledgements}

We would like to express our heartfelt thanks to Lucja Matusikov PhD, Professor Michal Pruzinski, Professor Ruslan Abramov and Professor Sergei Ignatiev for conducting the survey among students from the Czech Republic, Slovakia, Russia and Latvia.

\section{Funding}

The publication is financed by a subsidy granted to the Cracow University of Economics. 


\section{Author contributions}

MT conceived the study and were responsible for the design and development of the data analysis. AS was responsible for data collection. MT was responsible for data interpretation. MT wrote the first draft and revised version of the article.

\section{Disclosure statement}

We do not have any competing financial, professional, or personal interests from other parties.

\section{References}

Abbasianchavari, A., \& Moritz, A. (2021). The impact of role models on entrepreneurial intentions and behavior: A review of the literature. Management Review Quarterly, 71(1), 1-40. https://doi.org/10.1007/s11301-019-00179-0

Ajzen, I. (1991). The theory of planned behavior. Organizational Behavior and Human Decision Processes, 50(2), 179-211. https://doi.org/10.1016/0749-5978(91)90020-T

Anlesinya, A., Adepoju, O. A., \& Richter, U. H. (2019). Cultural orientation, perceived support and participation of female students in formal entrepreneurship in the sub-Saharan economy of Ghana. International Journal of Gender and Entrepreneurship, 11(3), 299-322. https://doi.org/10.1108/IJGE-01-2019-0018

Bell, R. (2019). Predicting entrepreneurial intention across the university. Education + Training, 61(7/8), 815-831. https://doi.org/10.1108/ET-05-2018-0117

Bilder, C. R., \& Loughin, T. M. (2004). Testing for marginal independence between two categorical variables with multiple responses. Biometrics, 60(1), 241-248. https://doi.org/10.1111/j.0006-341X.2004.00147.x

Bilder, C. R., Loughin, T. M., \& Nettleton, D. (2000). Multiple marginal independence testing for pick any/c variables. Communications in Statistics - Simulation and Computation, 29(4), 1285-1316. https://doi.org/10.1080/03610910008813665

Boubker, O., Arroud, M., \& Ouajdouni, A. (2021). Entrepreneurship education versus management students' entrepreneurial intentions. A PLS-SEM approach. The International Journal of Management Education, 19(1), 100450. https://doi.org/10.1016/j.ijme.2020.100450

Branchet, B., \& Kř́žzová, A. (2015). Gender and entrepreneurial intentions in a transition economy context: Case of the Czech Republic. International Journal of Entrepreneurship and Small Business, 25(3), 260. https://doi.org/10.1504/IJESB.2015.069696

Capelleras, J. L., Contín-Pilart, I., Martin-Sanchez, V., \& Larraza-Kintana, M. (2013). The influence of individual perceptions and the urban/rural environment on nascent entrepreneurship. Investigaciones Regionales-Journal of Regional Research, 26, 97-113. https://old.aecr.org/images/ImatgesArt icles/2013/10/5Capelleras.pdf

Central Statistical Bureau of Latvia. (2019). Lower birth and migration rates recorded in Latvia. Retrieved February 9, 2020, from https://www.csb.gov.lv/en/statistics/statistics-by-theme/population/ number-and-change/search-in-theme/2444-number-population-latvia-2018

Çera, G., Cepel, M., Zakutna, S., \& Rozsa, Z. (2018). Gender differences in perception of the university education quality as applied to entrepreneurial intention. Journal of International Studies, 11(3), 147-160. https://doi.org/10.14254/2071-8330.2018/11-3/13 
Egerová, D., Eger, L., \& Mičík, M. (2017). Does entrepreneurship education matter? Business students' perspectives. Tertiary Education and Management, 23(4), 319-333.

https://doi.org/10.1080/13583883.2017.1299205

Fullerton, A. S. (2009). A conceptual framework for ordered logistic regression models. Sociological Methods \& Research, 38(2), 306-347. https://doi.org/10.1177/0049124109346162

Gill, S. A., Bencheva, N., Karayel, S., \& Usman, M. (2021). Does entrepreneurial self-efficacy moderate effects of cognitive flexibility and entrepreneurial alertness on entrepreneurial intentions? Entrepreneurial Business and Economics Review, 9(3), 25-41. https://doi.org/10.15678/EBER.2021.090302

Gubik, A. S. (2021). Entrepreneurial career: Factors influencing the decision of Hungarian students. Entrepreneurial Business and Economics Review, 9(3), 43-58. https://doi.org/10.15678/EBER.2021.090303

Hofstede, G. (1991). Cultures and organizations: Software of the mind. McGraw-Hill. https://www.worldcat.org/title/cultures-and-organizations-software-of-the-mind/oclc/23015181

Hofstede Insights. (2020). Country comparison. Retrieved February 9, 2020, from https://www.hofstedeinsights.com

Iakovleva, T., \& Solesvik, M. Z. (2014). Entrepreneurial intentions in post-Soviet economies. International Journal of Entrepreneurship and Small Business, 21(1), 79-100. https://doi.org/10.1504/IJESB.2014.057916

Kofanova, T. (1997). Emergence of youth entrepreneurship. In S. P. Sirotkin (Ed.), Conditions and factors of forming of the Russian entrepreneurship (pp. 64-65). Kostroma State Technical University.

Kurczewska, A., \& Białek, J. (2014). Is the interplay between self-efficacy and entrepreneurial intention gender-dependent? Argumenta Oeconomica, 2(33), 23-38. https://doi.org/10.15611/aoe.2014.2.02

Levesque, M., \& Minniti, M. (2006). The effect of aging on entrepreneurial behavior. Journal of Business Venturing, 21(2), 177-194. https://doi.org/10.1016/j.jbusvent.2005.04.003

Moreno-Gómez, J., Gómez-Araujo, E., \& Castillo-De Andreis, R. (2019). Parental role models and entrepreneurial intentions in Colombia: Does gender play a moderating role? Journal of Entrepreneurship in Emerging Economies, 12(3), 413-429. https://doi.org/10.1108/JEEE-04-2019-0048

Moriano, J. A., Gorgievski, M., Laguna, M., Stephan, U., \& Zarafshani, K. (2012). A cross-cultural approach to understanding entrepreneurial intention. Journal of Career Development, 39(2), 162-185. https://doi.org/10.1177/0894845310384481

Moussa, N. B., \& Kerkeni, S. (2021). The role of family environment in developing the entrepreneurial intention of young Tunisian students. Entrepreneurial Business and Economics Review, 9(1), 31-45. https://doi.org/10.15678/EBER.2021.090102

Nowiński, W., \& Haddoud, M. Y. (2019). The role of inspiring role models in enhancing entrepreneurial intention. Journal of Business Research, 96, 183-193. https://doi.org/10.1016/j.jbusres.2018.11.005

Nowiński, W., Haddoud, M. Y., Lančarič, D., Egerová, D., \& Czeglédi, C. (2019). The impact of entrepreneurship education, entrepreneurial self-efficacy and gender on entrepreneurial intentions of university students in the Visegrad countries. Studies in Higher Education, 44(2), 361-379. https://doi.org/10.1080/03075079.2017.1365359

Okręglicka, M., Havierniková, K., Mynarzová, M., \& Lemańska-Majdzik, A. (2017). Entrepreneurial intention creation of students in Poland, Slovakia and Czechia. Polish Journal of Management Studies, 15(2), 162-172. https://doi.org/10.17512/pjms.2017.15.2.15

Pawlak, A. (2016). The influence of gender on the entrepreneurial intention of Polish high school students. Studia Oeconomica Posnaniensia, 4(5), 25-37. https://doi.org/10.18559/SOEP.2016.5.2

Pfeifer, S., Šarlija, N., \& Zekić Sušac, M. (2016). Shaping the entrepreneurial mindset: Entrepreneurial intentions of business students in Croatia. Journal of Small Business Management, 54(1), 102-117. https://doi.org/10.1111/jsbm.12133 
Rantanen, T., Pawlak, A., \& Toikko, T. (2015). The significance of social welfare attitudes in young people's entrepreneurial intentions. Entrepreneurial Business and Economics Review, 3(1), 43-60. https://doi.org/10.15678/EBER.2015.030104

Schwarz, E. J., Wdowiak, M. A., Almer-Jarz, D. A., \& Breitenecker, R. J. (2009). The effects of attitudes and perceived environment conditions on students' entrepreneurial intent. Education + Training, 51(4), 272-291. https://doi.org/10.1108/00400910910964566

Shinnar, R. S., Hsu, D. K., \& Powell, B. C. (2014). Self-efficacy, entrepreneurial intentions, and gender: Assessing the impact of entrepreneurship education longitudinally. The International Journal of Management Education, 12(3), 561-570. https://doi.org/10.1016/j.ijme.2014.09.005

Solesvik, M. (2013). Entrepreneurial motivations and intentions: Investigating the role of education major. Education + Training, 55(3), 253-271. https://doi.org/10.1108/00400911311309314

Solesvik, M., Westhead, P., \& Matlay, H. (2014). Cultural factors and entrepreneurial intention: The role of entrepreneurship education. Education + Training, 56(8/9), 680-696.

https://doi.org/10.1108/ET-07-2014-0075

Solesvik, M., Westhead, P., Matlay, H., \& N. Parsyak, V. (2013). Entrepreneurial assets and mindsets: Benefit from university entrepreneurship education investment. Education + Training, 55(8/9), 748-762. https://doi.org/10.1108/ET-06-2013-0075

Trung, T. L., Xuan, H. D., Ngoc, H. N., Cong, D. D., \& Phuong, L. N. T. (2020). A comparative analysis of entrepreneurial intention and migration attitudes of students in Vietnam and Poland. Management Science Letters, 10, 479-488. https://doi.org/10.5267/j.msl.2019.8.022

Wach, K., \& Wojciechowski, L. (2016). Entrepreneurial intentions of students in Poland in the view of Ajzen's theory of planned behaviour. Entrepreneurial Business and Economics Review, 4(1), 83-94. https://doi.org/10.15678/EBER.2016.040106

Wąsowska, A. (2016). Who doesn't want to be an entrepreneur? The role of need for closure in forming entrepreneurial intentions of Polish students. Entrepreneurial Business and Economics Review, 4(3), 27-39. https://doi.org/10.15678/EBER.2016.040303

Westhead, P., \& Solesvik, M. (2016). Entrepreneurship education and entrepreneurial intention: Do female students benefit? International Small Business Journal: Researching Entrepreneurship, 34(8), 979-1003. https://doi.org/10.1177/0266242615612534

Zhang, P., Wang, D. D., \& Owen, C. L. (2015). A study of entrepreneurial intention of university students. Entrepreneurship Research Journal, 5(1), 61-82. https://doi.org/10.1515/erj-2014-0004

Ziemiański, P. (2018). Family business experience and the probability of starting a venture: Gender differences in Poland. Journal of East European Management Studies, 23(4), 603-620.

https://doi.org/10.5771/0949-6181-2018-4-603 